http://jmscr.igmpublication.org/home/ ISSN (e)-2347-176x ISSN (p) 2455-0450 crossref DOI: https://dx.doi.org/10.18535/jmscr/v9i10.26

\title{
Assessment of SPEM1 Expression and Inhibin B in Patients with Dysfunctional Azoospermia and Their Relation to Successful Sperm Retrieval
}

\section{Authors \\ Tarek M. Hussein', Adel H. El Beheiry', Walid M. Ahmed ${ }^{1}$, Raghda Saad Zaghloul Taleb ${ }^{2}$}

${ }^{1}$ Dermatology, Venereology and Andrology Department, Faculty of Medicine, Alexandria University, Alexandria, Egypt

${ }^{2}$ Clinical and Chemical Pathology Department, Faculty of Medicine, Alexandria University, Alexandria,

Egypt

*Corresponding Author

Walid Marei Ahmed

Resident, Department of Dermatology, Venereology and Andrology, Alexandria University, 21561

Alexandria, Egypt

ORCID ID: 0000-0003-2200-8719

\begin{abstract}
For successful sperm retrieval in azoospermic men, a reliable prediction of success rate is necessary. The aim of this study is to assess the gene expression of SPEMI in testicular tissue and serum inhibin B levels in patients with primary azoospermia and to evaluate their predictive power for sperm retrieval.

Material and Methods: 60 non-obstructive azoospermic patients and 20 obstructive azoospermic patients undergoing testicular tissue microdissection for intracytoplasmic sperm injection were studied. SPEMI gene expression was analyzed by real-time reverse transcription-polymerase chain reaction using the DDCt method. Chemiluminescence technique was used to measure the levels of serum inhibin B.

Results: The relative expression of SPEM1 and serum inhibin B levels were significantly lower in patients compared to controls. The relative expression of SPEMI and serum inhibin B levels was significantly higher in patients with positive sperm retrieval than patients with negative sperm retrieval. A positive correlation was found between SPEMI relative expression and serum Inhibin B levels in the studied group.
\end{abstract}

Conclusion: Results suggest that SPEMI and serum inhibin B can both be utilized in predicting the success of sperm retrieval. SPEMI could be considered a stronger predictor of sperm retrieval than serum inhibin $B$.

Keywords: Azoospermi, Inhibin B, Microdissection testicular sperm extraction, SPEM, Sperm retrieval.

\section{Introduction}

Infertility is becoming a major public health concern with significant psychological and economic impacts ${ }^{[1]}$. Globally, Up to $15 \%$ of couples suffer from infertility, in which almost a quarter of the cases is due to the male factor ${ }^{[2]}$. Azoospermia refers to the complete lack of spermatozoa in the ejaculate affecting $1 \%$ of all 
males and up to $15 \%$ of the infertile male population $^{[3]}$. Azoospermia can be categorized into obstructive azoospermia (OA); that is due to blockage along the male reproductive tract and nonobstructive azoospermia (NOA): that is due to dysfunctional spermatogenesis affecting about $60 \%$ of azoospermic men ${ }^{[4]}$. Both cases of NOA and OA can benefit from testicular sperm extraction (TESE) [4]

In cases of NOA, micro-TESE has improved the chances of sperm retrieval by identifying foci of spermatogenesis in the testis with a success rate of $40-60 \%$. In order to improve this outcome, it is necessary to have a reliable predictor of sperm retrieval $^{[5]}$.

Several clinical parameters such as semen analysis, testicular size, follicle-stimulating hormone (FSH) levels, inhibin B, and histopathology are among predictive factors for successful sperm retrieval in men with dysfunctional azoospermia. However, no accurate predictors have been identified. ${ }^{[6-8]}$

Serum inhibin B (a heterodimer glycoprotein synthesized by Sertoli cells) has been shown in several studies to predict spermatogenesis ${ }^{[9]}$. On the contrary, other studies failed to show that inhibin B can predict sperm retrieval ${ }^{[8]}$.

Mounting evidence have shown that spermatogenesis failure could be predicted by analysing germ cell-specific genes involved in spermatogenesis. ${ }^{[10,11]}$. For instance, several molecular markers, including SPEM1, were analyzed by Hashemi et al. (2018) in testicular samples in patients undergoing microTESE for ICSI to evaluate their relation with sperm retrieval. SPEM1 had the highest predictive power hence the best molecular marker for predicting sperm retrieval [12].

SPEM1 (spermatid maturation 1) is a 330 amino acid protein that is expressed in the cytoplasm of stages 14-16 elongated spermatids and is necessary in the removal of cytoplasm during spermiogenesis. SPEM1 Knockout mice show deformed sperms in addition to male infertility ${ }^{[13]}$.

In view of the scarcity of studies on SPEM1 in predicting sperm retrieval in the literature and the lack of studies in our ethnic population, there is an unmet need to determine its value in this set-up. Thus, the present study aimed to analyze SPEM1 in testicular samples and serum inhibin B in patients undertaking micro-TESE for ICSI and their correlation with sperm retrieval.

\section{Materials and Methods}

We recruited eighty patients from the Andrology outpatient clinic of the Main University Hospital, Faculty of Medicine, University of Alexandria. 60 NOA patients with verified azoospermiaas per the WHO $5^{\text {th }}$ edition $^{[14]}$, normal quantity of serum fructose and alpha glucosidase and no evidence of obstructive causes of azoospermia in history or physical examination were included. Patients with evidence of obstruction, anejaculation, and retrograde ejaculation were excluded from the study. The control group consisted of twenty (out of 80) patients who had obstructive azoospermia (OA). After the study protocol was approved by the Research Ethics Committee (REC) of Alexandria University, all the patients provided informed consent to participate in this research.

\section{Sperm Extraction}

A longitudinal incision of about two $\mathrm{cm}$ on the median raphe of the scrotum was made, extending to the tunica vaginalis, exposing the tunica albuginea. Optical magnification of X6 - 8 was employed to observe blood vessels beneath the tunica vaginalis, a single wide equatorial incision was made, which allowed extensive visualization of seminiferous tubules without damaging the vasculature of the testis. With the help of an operating microscope at a magnification of $\mathrm{x} 20$ 25, particular seminiferous tubules larger than the rest of the testicular tubes were identified, samples of 2-10 mg micro-TESE were sharply obtained from larger and more opaque tubules. ${ }^{[15]}$ The tissue surrounding each microdissected sample was then excised, and assessed the efficacy of sperm extraction with microdissection. Further smaller pieces of testicular tissue specimen were acquired to release spermatozoa from the seminiferous tubules. The suspension 
obtained was studied. Retrieved viable sperm were directly utilized for ICSI or cryopreserved at $-4^{\circ} \mathrm{C}$ in liquid nitrogen ${ }^{[16]}$.

Upon successful retrieval of spermatozoa, the procedure came to an end. Hemostasis was achieved by microbipolar cauterization, and the tunica albuginea closed with continuous suture. A single surgeon carried out all of the surgical procedures. Two extra pieces of testicular tissue were taken and fixed in Bouin's fixative solution for quantitative assessment of histopathological pattern and RNA stabilization reagent for quantitative expression of SPEM1.

\section{Histopathological Analysis}

By examining hematoxylin and eosin $(\mathrm{H}$ and $\mathrm{E})$ stained paraffin-embedded specimens, testicular histology was classified according to the most common histopathological pattern into 1) Hypospermatogenesis (HS), 2) Maturation arrest (MA), 3) Sertoli cell-only syndrome (SCOS) and 4) Tubular hyalinization $(\mathrm{TH})^{[17]}$.

\section{Determination of SPEM1 Gene Expression RNA Extraction and Reverse Transcription}

The stabilized tissue samples stored at $-80^{\circ} \mathrm{C}$ were first left to thaw; afterward, total RNA was extracted per the RN easy Mini Kit (Cat. No. 74104, QIAGEN, USA) manufacturer's instructions. The RNA concentration and purity were assessed using Nano Drop 2000c Spectrophotometer (Thermo Fisher Scientific, USA). All genomic RNA was converted into single-stranded complementary DNA (cDNA) using a High-Capacity cDNA Reverse Transcription Kit (Cat. No. 4368814, Applied Biosystems $^{\mathrm{TM}}$, USA). Reverse transcription (RT) was carried out using Arktik thermal cycler (Thermo Fisher Scientific, USA) at $25^{\circ} \mathrm{C}$ for ten minutes, $37^{\circ} \mathrm{C}$ for 2 hours, and $85^{\circ} \mathrm{C}$ for five minutes, then held at $4^{\circ} \mathrm{C}$.

\section{Quantitative Real-time PCR (qPCR)}

Relative quantification of SPEM1 gene expression was performed using Maxima SYBR Green/ROX qPCR Master Mix (2x) (Cat. No. \# K0221, Thermo
Fisher Scientific, USA) using Strata gene Mx3000P PCR System (Agilent, USA) according to manufacturer instructions. Custom-made primers were supplied by Applied Biosystems, USA, including four unlabeled sequence-specific forward and reverse primers to amplify cDNA of SPEM1 and cDNA of GAPDH as a housekeeping gene. The sequence of the primers was as follows: SPEMI forward primer

5 -

TAACATTAGCATCAATATAGTG-3' and reverse 5'-GTCTGCTTTCTGAGTAAT-3'; GAPDH forward primer 5'CCACTCCTCCACCTTTGACG-3' and reverse 5'CCACCACCCTGTTGCTGTAG -3'. Relative expression was calculated using the $2^{-\Delta \Delta \mathrm{CT}}$ method ${ }^{[18]}$. The PCR reactions were carried out in duplicate with a final volume of $25 \mu \mathrm{L}$, including $12.5 \mu \mathrm{L}$ Maxima SYBR Green/ROX qPCR Master Mix (2X), $1 \mu \mathrm{L}$ forward primer (10 pmole), $1 \mu \mathrm{L}$ reverse primer (10 pmole), $0.05 \mu \mathrm{L} 10 \mathrm{x}$ diluted ROX solution, cDNA (200 ng) and nuclease-free water to a final volume of $25 \mu \mathrm{L}$. The reaction protocol was as follows: $10 \mathrm{~min}$ at $95^{\circ} \mathrm{C}$ (one cycle) for initial denaturation, followed by 40 cycles of $15 \mathrm{~s}$ at $95^{\circ} \mathrm{C}$ for denaturation and annealing/extension for $60 \mathrm{~s}$ at $45^{\circ} \mathrm{C}$.

\section{Statistical Analysis}

The IBM SPSS software package version 20.0 was used to examine the data (Armonk, NY: IBM Corp). The Kolmogorov-Smirnov test, the Chi-square, the student t-test, Pearson coefficient, the Spearman coefficient, and the Kruskal Wallis test were used accordingly. Receiver operating characteristic curve (ROC) was used to evaluate the test's diagnostic performance. A p-value of $<.05$ was considered significant.

\section{Results}

The mean age of patients with non-obstructive azoospermia was $31.07 \pm 7.11$ vs. $29.10 \pm 3.43$ in the control group and was comparable between the two groups $(\mathrm{p}=0.105)$.

\section{Serum Inhibin B}

The NOA patients had significantly lower serum inhibin $\mathrm{B}$ than the $\mathrm{OA}$ controls with a median of 
$37.70 \mathrm{pg} / \mathrm{mL}$ (range: $2.0-238.0 \mathrm{pg} / \mathrm{mL}$ ) vs 155.2 $\mathrm{pg} / \mathrm{mL}$ (range: 79.20 - $303.0 \mathrm{pg} / \mathrm{mL}$ ), respectively, $\mathrm{p}<0.001$. (Figure 1A).
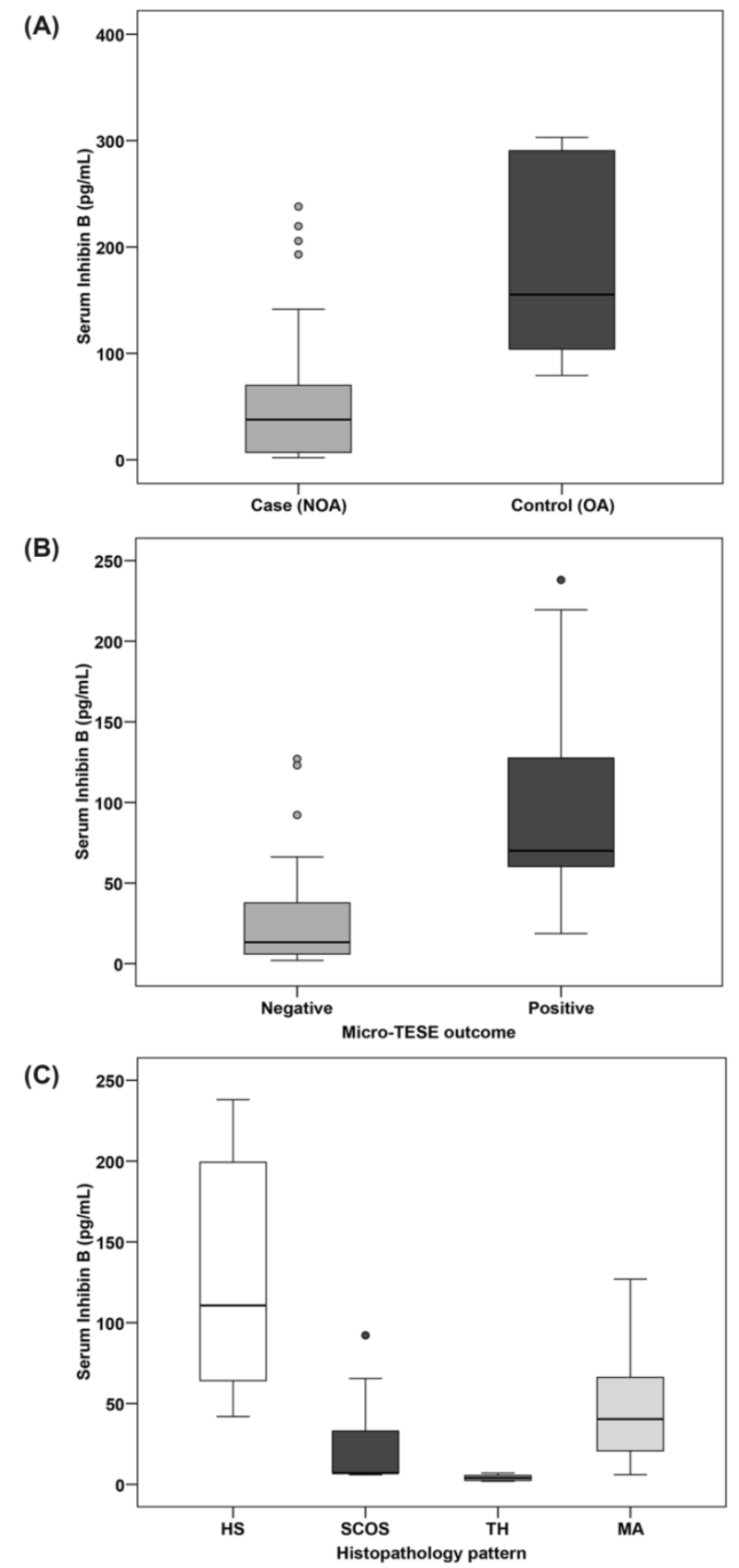

Figure. 1 (A-C)

Figure 1A. Comparison between the two studied groups (NOA vs OA) according to Inhibin B $(\mathrm{Pg} / \mathrm{mL})$ levels; B. Serum Inhibin B levels in relation to Micro-TESE outcome in Cases (NOA) (n = 60); C. Serum Inhibin B levels in different histopathology pattern (HS-Hypospermatogenesis; SCOS- Sertoli cell only syndrome; TH-Tubular Hyalinization; MA-maturation arrest) in Cases $(\mathrm{NOA})(\mathrm{n}=60)$
The level of serum inhibin B was statistically significantly higher in cases with positive microTESE outcomes than cases with negative outcomes $(p<0.001)$ (Figure 1B). Inhibin B levels in the patients grouped according to the histopathological pattern are shown in Figure 1C. Serum level of inhibin B was highest in hypospermatogenesis (median=110.7 $\mathrm{pg} / \mathrm{mL}$ ) and lowest in tubular hyalinization (median $=4.0 \mathrm{pg} / \mathrm{mL}$ ), in maturation arrest and SCOS the median values were 40.40 $\mathrm{pg} / \mathrm{mL}$ and $7.0 \mathrm{pg} / \mathrm{mL}$ respectively. (Figure 1C)

Serum FSH and inhibin B had a significant negative correlation $(\mathrm{r}=-0.595, \mathrm{p}<0.001)$ whereas, SPEM1 relative expression had a significant positive correlation with serum inhibin B. $(r=0.621$, $\mathrm{p}<$ 0.001). (Table 1)

Relative SPEM1 expression was significantly lower in NOA patients (ranged from $0.02-1247.7$ with a median of 1.79) than in OA controls (ranged from 70.0 - 2098 with a median of 1174.6) $(\mathrm{p}<0.001)$ (Figure 2A). A statistically significant higher relative expression of SPEMI was observed in cases with successful sperm retrieval than cases without sperm retrieval ( $\mathrm{p}=0.001)$. (Figure 2B).

The relative expression of SPEM1 in patients with non-obstructive azoospermia was highest in hypospermatogenesis (median=824.4) and lowest in SCOS (median=0.13), in tubular hyalinization and maturation arrest, the medians were 0.17 and 3.11 respectively ( $\mathrm{p}<0.001$ ). (Figure $2 \mathrm{C}$ ). In addition, a negative correlation between SPEMI expression and FSH level was observed ( $\mathrm{r}=-0.582)$. (Table 1) 
Table (1): Correlation between serum Inhibin B, SPEMI and FSH in cases group (NOA) (n = 60)

\begin{tabular}{lcc}
\hline & $\mathbf{r}_{\mathrm{s}}$ & $\mathbf{P}$ \\
\hline Serum Inhibin B $(\mathbf{p g} / \mathrm{mL})$ and FSH $(\mathbf{m I U} / \mathbf{m L})$ & -0.595 & $<0.001^{*}$ \\
SPEM1 relative expression and FSH $(\mathrm{mIU} / \mathrm{mL})$ & -0.582 & $<0.001^{*}$ \\
Serum Inhibin B $(\mathbf{p g} / \mathrm{mL})$ and SPEM1 relative & 0.621 & $<0.001^{*}$ \\
expression
\end{tabular}

$\mathrm{r}_{\mathrm{s}}$ : Spearman coefficient

*: Statistically significant at $\mathrm{p} \leq 0.05$

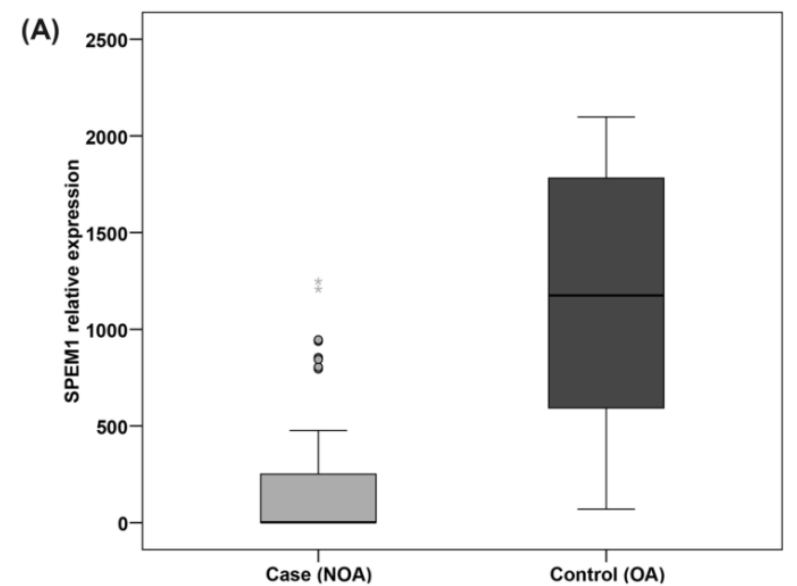

(B)

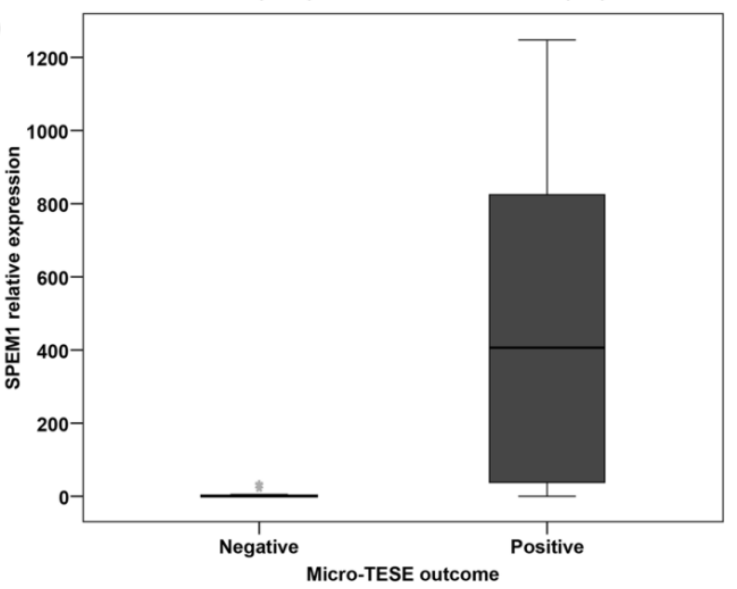

(C)

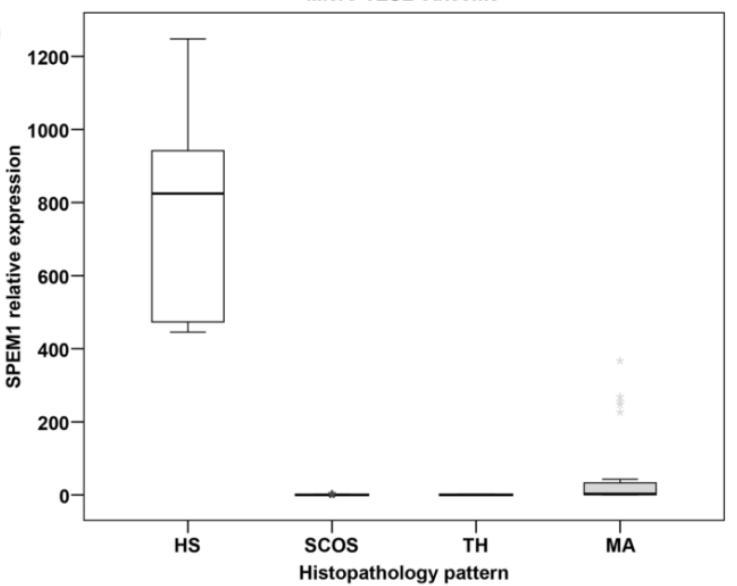

Figure 2 (A-C).

A. SPEM1 relative expression in cases and control;

B. SPEM1 relative expression in relation to MicroTESE outcome in Cases (NOA) $(\mathrm{n}=60)$;

C. SPEM1 relative expression in different histopathology pattern (HS-Hypospermatogenesis;
SCOS- Sertoli cell only syndrome;TH-Tubular Hyalinization; MA-maturation arrest) in Cases $(\mathrm{NOA})(\mathrm{n}=60)$

\section{ROC Curve Analysis}

The diagnostic value of SPEMI and serum inhibin B for sperm retrieval was assessed using ROC curves. As shown in Figure 3, the best cut-off value of serum inhibin B was $>50.8 \mathrm{pg} / \mathrm{mL}$. Under the cut-off value, AUC was 0.875 , specificity $83.33 \%$, sensitivity $79.17 \%$, and accuracy $81.67 \%$, whereas the best cut-off value of SPEM1 was $>2.8$. Under the cut-off value, AUC was 0.909, specificity of 86.11 , the sensitivity of 91.67 , and accuracy of 88.33. This data suggest that SPEMI has better predictive power than serum inhibin B.

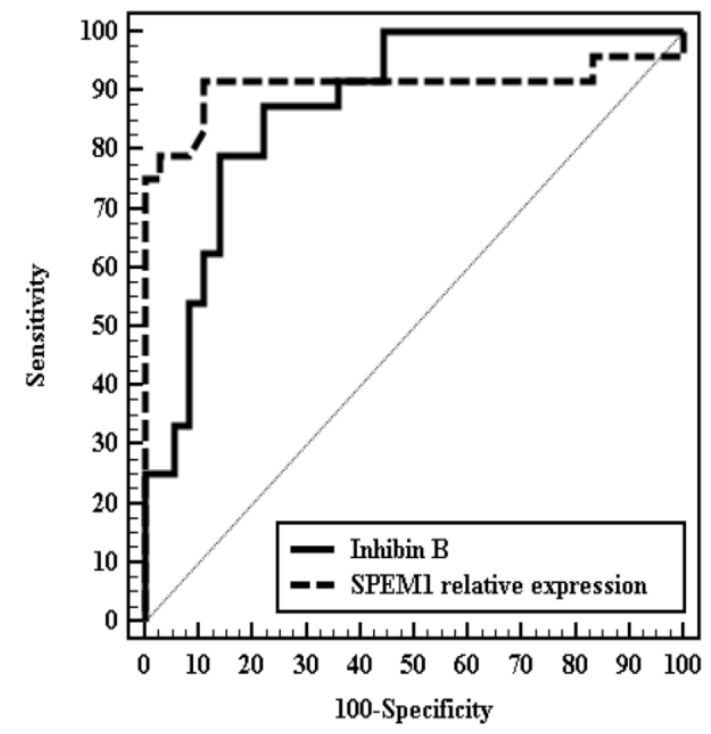

Figure 3 ROC curve for Inhibin B and SPEMI relative expression to discriminate Retrieval patients $(n=24$ vs. 36$)$ in cases (NOA) groups

\section{Discussion}

Micro-TESE has been considered a more efficient method of sperm retrieval in dysfunctional azoospermia with minimal invasion than multiple biopsies. Conventional TESE has been associated 
with testicular atrophy, intratesticular bleeding, devascularisation, and scar formation, disrupting the hormone synthesis and spermatogenic pathway ${ }^{[19]}$.

Several authors reported that testicular histology is the best single predictor of micro-TESE, but its utility is restricted because the diagnosis requires an extra surgical operation. ${ }^{[20,21]}$

The histopathological patterns in the present study included; maturation arrest 30/60 (50\%), hypospermatogenesis $12 / 60$ (20\%), SCOS $10 / 60$ (16.7\%), and tubular hyalinization 8/60 (13.3\%). There was positive sperm retrieval in $100 \%$ of the cases with hypospermatogenesis. On the contrary, SCOS and tubular hyalinization had a $0 \%$ chance of sperm retrieval, and there was a statistically significant association between testicular histopathology and micro-TESE outcome $(\mathrm{p}<0.001)$. These findings resonate with a study done by Seo et al. (2001), who demonstrated that cases with SCOS had a lower rate of sperm retrieval compared to cases with hypospermatogenesis and maturation $\operatorname{arrest}^{[22]}$. On the contrary, Tsujimura et al. (2002) reported a higher retrieval rate of $22.6 \%$ in cases of SCOS. This finding could be attributed to incomplete $\operatorname{SCOS}^{[23]}$.

The level of serum inhibin $B$ in NOA was substantially lower than in OA controls $(p<0.001)$. Meanwhile, when comparing the inhibin B level in the NOA cases, it was significantly higher in those patients with the positive micro-TESE outcome as opposed to patients with the negative micro-TESE outcome $(p<0.001)$. These results agree with the previous study done by Nagata et al. (2005). They found that the positive TESE group had statistically higher levels of serum inhibin B compared to the negative group ${ }^{[24]}$.

The present research revealed a significant negative correlation between FSH levels and serum inhibin B in NOA. Many studies have found a significant negative correlation between serum inhibin B levels and FSH levels. IIlingworth et al.(2009) also showed a negative correlation between serum inhibin $\mathrm{B}$ and $\mathrm{FSH}^{[25]}$. The role of inhibin $\mathrm{B}$ as negative feedback for FSH could explain this ${ }^{[25]}$.
In this study, inhibin B levels were statistically higher in cases that had positive sperm retrieval. The histopathological pattern and serum inhibin B had a significant correlation. Inhibin B levels were higher in cases of hypospermatogenesis with positive sperm retrieval. On the other hand, serum inhibin B was lower in cases of SCOS and tubular hyalinization with negative sperm retrieval. These findings agree with Anawalt et al. (1996) and De Krester et al. (1989), who reported that serum inhibin B levels were lower in patients with SCOC and tubular hyalinization and higher in hypospermatogenesis. ${ }^{[25,26]}$

The ROC curve was utilized to examine the predictive potential of serum inhibin $\mathrm{B}$ in sperm retrieval in order to obtain a more reliable prediction. We found that serum inhibin B had an area under the curve of 0.903 , with a cut-off value of $>50.8 \mathrm{pg} / \mathrm{ml}$ and an accuracy of $80 \%$.

There are significant differences in the computed cut-off value in other research. Ballesca et al. (2002) obtained a cut-off value of $40 \mathrm{pg} / \mathrm{mL}$ that was close to our study, with a $90 \%$ sensitivity and $100 \%$ specificity $^{[9]}$. Some studies had a cut-off value lower than our cut-off value. Ziaee et al. (2006) and Alhalabi et al. (2016) reported a cut-off value of $27.5 \mathrm{pg} / \mathrm{mL}$ and $35 \mathrm{pg} / \mathrm{mL}$, respectively ${ }^{[27,28]}$. In contrast, Bonarriba et al.(2013) and Wang et al. (2020) reported a higher cutoff value of $67 \mathrm{pg} / \mathrm{mL}$ and $77.72 \mathrm{pg} / \mathrm{mL}$ respectively [29,30]. This could be attributed to variation in sample size and different ethnicity.

SPEM1 gene expression was analyzed in testicular biopsies of 30 NOA cases and 10 OA controls. There was a significantly decreased expression of SPEM1 in the NOA cases compared to the normal spermatogenesis in the OA group.

SPEM1 relative expression was considerably lower in patients who had negative sperm retrieval compared to those with positive sperm retrieval in the NOA group. SPEM1 relative expression was highest in hypospermatogenesis (median=824.45). In all the 6 cases, there was a positive micro-TESE outcome, whereas SPEM1 relative expression was lowest in SCOS and tubular hyalinization patients 
(median=0.11 and 0.18 respectively), of whom both groups had a negative micro-TESE outcome.

In line with our findings, Hashemi et al. (2018) assessed seven molecular markers, including SPEM1 to predict the success of sperm retrieval ${ }^{[12]}$. They concluded that SPEM1 expression reduced significantly in patients with NOA compared with normal spermatogenesis (OA). In addition, SPEM1 expression also reduced significantly in patients with negative sperm retrieval compared to positive sperm retrieval ${ }^{[12]}$.

Using ROC curve analysis of SPEM1, a cut-off value of $>1.88$ and AUC of 0.824 were obtained. Hashemi et al. (2018) also concluded that the most predictive marker of micro-TESE outcome was SPEM1 with a cut-off value and AUC of 0.086 and 0.91 , respectively ${ }^{[12]}$. This is the only study in the literature to assess the cut-off value of SPEM1 in predicting sperm retrieval.

The present study showed that SPEM1 was a more sensitive predictor of sperm retrieval than serum inhibin B in NOA patients. The area under the ROC curve for SPEM1 was significantly larger than that of serum inhibin B.

The current work has opened up new avenues for future research into SPEM1's predictive power in sperm retrieval. Further research should be conducted on a large population of cases and controls to analyze the expression of SPEM1 and inhibin B semen samples and evaluate their association with sperm retrieval.

\section{Conclusions}

The present study revealed that SPEM1 and serum inhibin B could be utilized in predicting the success of sperm retrieval. However, SPEM1 could be considered a stronger predictor of sperm retrieval than serum inhibin B.

\section{Funding}

This research did not receive any specific grant from funding agencies in the public, commercial, or not-for-profit sectors.

\section{References}

1. Mascarenhas MN, Flaxman SR, Boerma T, Vanderpoel S, Stevens GA. National, Regional, and Global Trends in Infertility Prevalence Since 1990: A Systematic Analysis of 277 Health Surveys. PLoS Med 2012;9:1-12.

doi.org/10.1371/journal.pmed.1001356.

2. Gurunath S, Pandian Z, Anderson RA, Bhattacharya S. Defining infertility-a systematic review of prevalence studies. Hum Reprod Update 2011;17:575-88. doi.org/10.1093/humupd/dmr015.

3. Cocuzza M, Alvarenga C, Pagani R. The epidemiology and etiology of azoospermia. Clinics (Sao Paulo) 2013;68:15-26. doi: 10.6061/clinics/2013(sup01)03.

4. Wosnitzer M, Goldstein M, Hardy MP. Review of Azoospermia. Spermatogenesis 2014;4:e28218. doi.10.4161/spmg. 28218.

5. Donoso P, Tournaye H, Devroey P. Which is the best sperm retrieval technique for nonobstructive azoospermia? A systematic review. Hum Reprod Update 2007;13:53949. doi.org/10.1093/humupd/dmm029.

6. Tournaye H, Liu J, Nagy PZ, Camus M, Goossens A, Silber S, et al. Correlation between testicular histology and outcome after intracytoplasmic sperm injection using testicular spermatozoa. Hum Reprod 1996;11:127-32.

doi.org/10.1093/oxfordjournals.humrep.a01 9004.

7. Jezek D, Knuth UA, Schulze W. Successful testicular sperm extraction (TESE) in spite of high serum follicle stimulating hormone and azoospermia: correlation between testicular morphology, TESE results, semen analysis and serum hormone values in 103 infertile men. Hum Reprod 1998;13:1230-4. doi.org/10.1093/humrep/13.5.1230.

8. von Eckardstein S, Simoni M, Bergmann M, Weinbauer GF, Gassner P, Schepers AG, et al. Serum inhibin $B$ in combination with serum follicle-stimulating hormone (FSH) is 
a more sensitive marker than serum FSH alone for impaired spermatogenesis in men, but cannot predict the presence of sperm in testicular tissue samples. J Clin Endocrinol Metab 1999;84:2496-501. doi: 10.1210/jcem.84.7.5855.

9. Ballesca JL. Serum inhibin B determination is predictive of successful testicular sperm extraction in men with non-obstructive azoospermia. Hum Reprod 2002;15:1734-8. doi.org/10.1093/humrep/15.8.1734.

10. Kleiman SE, Yogev L, Hauser R, Botchan A, Maymon BB, Paz G, et al. Expression profile of AZF genes in testicular biopsies of azoospermic men. Hum Reprod 2007; 22:151-8. doi.org/10.1093/humrep/del341.

11. Lardone MC, Parodi DA, Valdevenito R, Ebensperger M, Piottante A, Madariaga M, et al. Quantification of DDX3Y, RBMY1, DAZ and TSPY mRNAs in testes of patients with severe impairment of spermatogenesis. Mol Hum Reprod 2007;13:705-12. doi.org/10.1093/molehr/gam057.

12. Hashemi MS, Mozdarani H, Ghaedi K, Nasr-Esfahani MH. Among seven testisspecific molecular markers, SPEM1 appears to have a significant clinical value for prediction of sperm retrieval in azoospermic men. Andrology 2018;6:890-5. doi.org/10.1111/andr.12528.

13. Zheng H, Stratton CJ, Morozumi K, Jin J, Yanagimachi R, Yan W. Lack of Spem1 causes aberrant cytoplasm removal, sperm deformation, and male infertility. Proc Natl Acad Sci 2007;104:6852-7. doi.org/10.1073/pnas.0701669104.

14. World Health Organization. WHO laboratory manual for the examination and processing of human semen. 5th ed. Geneva: World Health Organization; 2010.

15. Schlegel PN. Testicular sperm extraction: microdissection improves sperm yield with minimal tissue excision. Hum Reprod 1999;14:131-5. doi: 10.1093/humrep/14.1.131.
16. Bernie AM, Mata DA, Ramasamy R, Schlegel PN. Comparison of microdissection testicular sperm extraction, conventional testicular sperm extraction, and testicular sperm aspiration for nonobstructiveazoospermia: a systematic review and meta-analysis. FertilSteril 2015;104: 1099-103.e1-3. doi: 10.1016/j.fertnstert.2015.07.1136.

17. Ezeh UI, Martin M, Cooke ID, Moore HD. Correlation of testicular pathology and sperm extraction in azoospermic men with ejaculated spermatids detected by immunofluorescent localization. Hum Reprod 1998;13:3061-5. doi: 10.1093/humrep/13.11.3061.

18. Livak KJ, Schmittgen TD. Analysis of relative gene expression data using real-time quantitative PCR and the $2-\Delta \Delta \mathrm{CT}$ method. Methods 2001;25:402-8. doi.org/10.1006/meth.2001.1262.

19. Schlegel PN. Testicular sperm extraction: microdissection improves sperm yield with minimal tissue excision. Hum Reprod 1999;14:131-5. doi: 10.1093/humrep/14.1.131.

20. Abdel Raheem A, Garaffa G, Rushwan N, De Luca F, Zacharakis E, Abdel Raheem T, et al. Testicular histopathology as a predictor of a positive sperm retrieval in men with non- obstructive azoospermia. BJU Int 2013;111:492-9. doi: 10.1111/j.1464410X.2012.11203.x.

21. Bernie AM, Ramasamy R, Schlegel PN. Predictive factors of successful microdissection testicular sperm extraction. Basic ClinAndrol 2013;23:1-7. doi.org/10.1186/2051-4190-23-5.

22. Seo JT, Ko WJ. Predictive factors of successful testicular sperm recovery in nonobstructive azoospermia patients. Int $\mathbf{J}$ Androl 2001;310:306-10. doi: 10.1046/j.1365-2605.2001.00307.x.

23. Tsujimura A, Matsumiya K, Miyagawa Y, Tohda A, Miura H, Nishimura K, et al. 
Conventional multiple or microdissection testicular sperm extraction: a comparative study. Hum Reprod 2002;17:2924-9. doi: 10.1093/humrep/17.11.2924.

24. Nagata Y, Fujita K, Banzai J, Kojima Y, Kasima K, Suzuki M, et al. Seminal plasma inhibin-B level is a useful predictor of the success of conventional testicular sperm extraction in patients with non-obstructive. $\mathbf{J}$ ObstetGynaecol Res 2005;31:384-8. doi: 10.1111/j.1447-0756.2005.00306.x.

25. Anawalt BD, Bebb RA, Matsumoto AM, Groome NP, Illingworth PJ, McNeilly AS, et al. Serum inhibin B levels reflect Sertoli cell function in normal men and men with testicular dysfunction.

ClinEndocrinolMetab 1996;81:3341-5. doi: 10.1210/jcem.81.9.8784094.

26. De Kretser DM, McLachlan RI, Robertson DM, Burger HG. Serum inhibin levels in normal men and men with testicular disorders. J Endocrinol 1989;120:517-23. doi.org/10.1677/joe.0.1200517.

27. Alhalabi M. Predictive value of serum Inhibin-B levels as an indicator of the presence of testicular spermatozoa in nonobstructive azoospermia. Middle East FertilSoc J 2016;21:246-52. doi.org/10.1016/j.mefs.2016.05.001.

28. Ziaee SA, Ezzatnegad M, Nowroozi M, Jamshidian H, Abdi H, HosseiniMoghaddam SM. Prediction of successful sperm retrieval in patients with nonobstructiveazoospermia. Urol J 2006;3:92-6. doi.org/10.22037/uj.v3i2.202.

29. Bonarriba CR, Burgués JP, Vidaña V, Ruiz $X$, Pizá P. Factorespredictivos de recuperaciónespermática en lasazoospermias. ActasUrolEsp 2013;37:266-72. doi.org/10.1016/j.acuro.2012.06.002.

30. Wang J, Lu N, Zhang S, Tang Z, Huang Y, $\mathrm{Li} \mathrm{W}$, et al. Reference range and cutoff value of serum inhibin $B$ to predict successful sperm retrieval: A cross-sectional study of $30 \quad 613$ Chinese men. ClinEndocrinol (Oxf) 2020;92:232-40. doi.org/10.1111/cen.14138. 